\title{
Some Remarks on History of Mathematical Problem Solving
}

\author{
BERND ZIMMERMANN
}

\begin{abstract}
In this contribution, it is our goal is to look on history of mathematics as a resource for a long-term study of mathematical problem solving processes and heuristics. In this way we intend to get additional information, e. g., about heuristics which proved to be extremely successful to create new mathematics. "Changing representation" and "false position" are examples of such strategies, which are illustrated by concrete examples to demonstrate the use for classroom teaching and teacher education. Our methods are based on hermeneutic principles.
\end{abstract}

Key words and phrases: problem solving, heuristic, history of mathematics.

ZDM Subject Classification: A30, D50, D59.

\section{Introduction}

Problem solving can be seen from quite different aspects. Some of these are as follows:

(1) Ubiquity: A problem is to be solved at the beginning of many mathematical activities - may it be a practical or a theoretical one. This was a normal situation during history (not only) of mathematics and still might happen very often in everyday situations.

(2) Person dependence: If a person tries to solve a problem, this person experiences a difficulty or a barrier. In contrast, a task can be solved by applying

The paper, based on a lecture hold at ICME 10 in Copenhagen 2004, TSG 18, Problem Solving. 
well known routine methods. Thus, it depends on the disposition and the experience of the respective person, too, whether a situation is a problem or a task $([20]$, p. $74,[23]$, p. 15).

E. g., it might be a problem, too, to (re-)construct basic methods of calculation for persons without formal schooling (as in so-called "streetmathematics", analyzed e.g. in [15]) .

(3) Context dependence:Furthermore, there are hints that sometimes experience in normal life seems to be more effective to foster some problem-solving abilities than instruction in formal methods at school: Kupari [12] reported results of a successive TIMSS-study, in which Finnish pupils outperformed students from all other countries (involved in that test) especially in the domain of probability. The Finnish pupils were the only ones who had no formal instruction at school in that domain before that testing!

Conclusion: there seem to be several good reasons to analyze mathematical problem solving processes in different settings and situations and from quite different perspectives.

Until now there are at least the following methods to analyze such processes:

- Observation of pupils in laboratories, in small groups and in (more or less) natural settings by using thinking aloud methods, interviews and other methods like introspection are very well known since many decades ([3], [5]).

- New technical possibilities (e. g. FMRT = functional magneto resonance tomography; PET = positron emission tomography) in brain research lead to very interesting results [22] which shed some new light on problem solving processes and furthermore they seem to support the basic statements of constructivist learning theory [6].

\section{Goal: Analyzing problem solving processes in the history of mathematics}

An additional method for getting more information about mathematical problem solving processes might be a careful analysis of testimonies from history of mathematics.

Some advantages of such method are as follows:

- There is especially the possibility of long term studies of cognitive processes and activities that cover several thousands of years. In this way, it might be more easy (than by analysis of individual problem solving processes) to 
highlight "invariants" (and variants) of thought processes and heuristics involved, which proved to be especially effective and productive for creating new mathematics. Such analysis might reveal more information about habits of thinking, too, that were connected with difficulties in problem solving and which might have hampered the development of mathematics.

- The huge amount of material might offer not only an analysis of problem solving processes across a long range of time but also across many different persons in very different social and cultural settings. In this way one might get additional information about individual differences in problem solving styles.

- In this way one might get further possibilities not only to test well known hypotheses about mathematical problem solving but also to generate some new ones.

- Knowledge about thinking processes at different times in different countries and different cultural settings might yield also additional possibilities to interpret and understand pupils' thinking processes of today. Thus, not only modern learning theories but also such knowledge might help to foster the diagnosis-competence of student teachers and (beginning) teachers.

- On the basis of such experience there might be supplementary consequences for educational action of today: Furthermore, one might get more support to carry out more effective instruction methods for differentiation.

- One might get also some help for curriculum planning (including development of standards). E. g., thinking methods - especially those ones, that proved to be useful already for several thousands of years - should be useful (with high probability) also for the next thirty or forty years. When dealing with applications in mathematics instruction - which is of course very important, too, and which was reinforced by PISA just recently - one has to be aware that it is much more difficult to make a prediction of future use of such more time depending settings. Hence, such studies might yield some possibilities to reduce the tendency of modernistic and populist determination of educational objectives.

Of course, there are also some risks and disadvantages combined with this approach:

- Historical texts normally have not been written to present or to reveal problem solving processes. 
- Furthermore, especially well-known books like the Elements of Euclid or the Chinese "Nine Chapters of Mathematical Technique" are compilations of several authors. Therefore, they are more the result of collective than individual problem solving processes.

- Because of the fact that the so called "original" text is very often the outcome of reiterated copying-procedures, it is often very difficult to judge the authenticity of a written text. So, it is also hard to learn something about the original thoughts of "the" author.

- Even in case of (obviously) original texts (as, e. g., very often in case of cuneiform-texts) one has the problem of translation and - consequently - of interpretation. One can try to minimize these problems by intensive studies of other texts about similar themes of the respective time. But, of course, there are also problems to interpret problem solving processes of pupils of today, because every observer is bound to his own observational framework and habits.

\section{Methods: How to analyze history of mathematics?}

The main method of analyzing and understanding historic testimonies is - of course - a hermeneutic one ([19], p. 132). Hermeneutics - originally concerned with the interpretation of ancient religious texts - is nowadays understood as a general method of human understanding and interpretation ([19], p. 132). Generally, we follow Kockelmans ([11], p. 83) (as cited in [19], p. 133):

"The task of hermeneutic interpretation is to critically examine ... foreknowledge of the world and of the phenomena we encounter there, with the intention of coming to a deeper comprehension of these phenomena .... The canons have no other function than to help us make explicit systematically what implicitly was already there before us."

These "canons" or rules of interpretation of historic testimonies are as follows ([19], p. 134):

The interpreter - e. g. of historic text - should try to

(1) Respect the autonomy of the object: The meaning of the object which he intends to study must not be projected into it; it must be derived from the phenomenon itself. So, one should strive for self-understanding of the phenomenon as far as possible. 
(2) Make the phenomenon maximally reasonable, e. g. making aware and reflecting possible prejudices about the meaning and the place value of the text of famous authors as, e. g., Euclid and Archimedes, due to other views on and understanding of mathematics of historians or mathematicians in modern times. Therefore, an appropriate approach to an adequate understanding of ancient texts can be achieved only from "neighboring" texts from the present or foregoing times.

(3) Get greatest possible familiarity with the phenomenon, taking into account the complexity of the object and its interrelatedness to other important aspects, e. g. other testimonies of the "same" author of the text or further translations and interpretations of other authors of the respective text.

(4) Show the meaning of the phenomenon (text) for his own situation. In this case, it is quite clear: We are interested in elements of thought processes and heuristics, which might be enclosed in the historic text of our inquiry.

(5) Follow the hermeneutic circle.

"The hermeneutic circle is essential a very general mode of the development of all human knowledge, namely the development through dialectic procedures. It is assumed that there cannot be any development of knowledge without some fore-knowledge. The anticipation of the global meaning of an action, a form of life, of a social institution, etc., becomes articulated through a dialectical process in which the meaning of the 'parts' or components is determined by the fore-knowledge of the 'whole', whereas our knowledge of the 'whole' is continuously corrected and deepened by the increase in our knowledge of the components." ([11], p. 85)

So, we have to follow at least the following three steps, perhaps repeatedly, forming a "loop":

a) We have to start with a previous knowledge of the object of our inquiry. We have some understanding of (specific) heuristics and their meaning and importance in our days. This understanding is mainly shaped by the work of G. Pólya ([16], [17], [18]).

b) With these goals and understandings in our "back head" (e. g. of "successive approximation", see below) we try to study historic testimonies with respect to corresponding and related thought processes to learn more about origins, development and impact. Interpretations and outcomes have to be checked very carefully.

c) Thus, we may come to a deeper and more differentiated understanding of heuristics and related or connected thought processes. In this way, we can 
come back after restructuring, refinement and augmentation of our original understanding to our starting point a), which can initiate inquiries for further studies in historic or cultural areas, not under consideration until now (cf. b)).

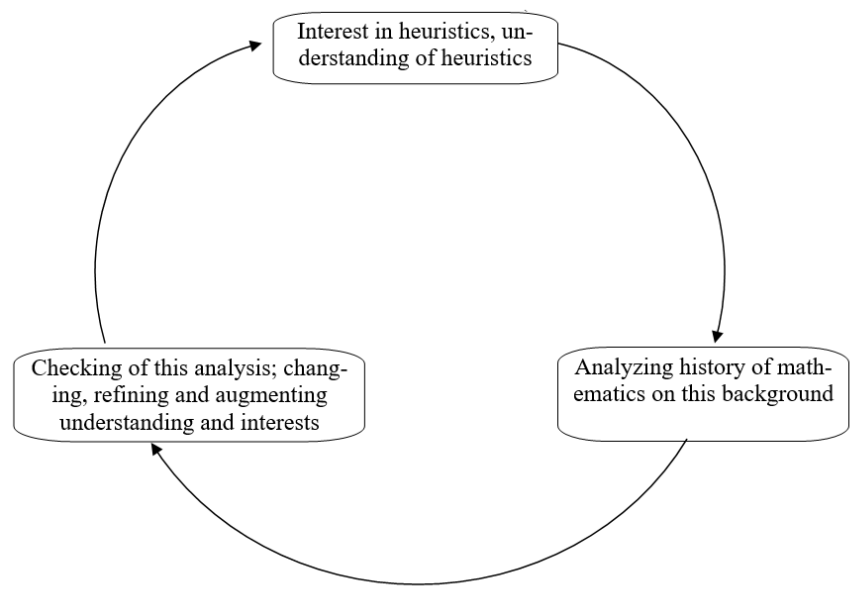

Figure 1

\section{Results: Spotlights on two strategies}

On the basis of these ideas we want to present two examples of problem solving strategies, which proved to be very effective as well in past as in present:

- changing representation,

- false position.

\section{Example 1: Changing representation}

Bruner [1] discussed different representation already some 60 years ago. Janvier [9] has edited a nice book on Problems of Representation in the Teaching and Learning of Mathematics. The NCTM 2000 [14] highlighted "Representation" as one of the key activities in mathematical problem solving. Seidel [21] proved the importance of different modalities of representation connected with mathematical giftedness by using modern methods of brain research. 
The solution of quadratic equations is one of the standard topics in normal mathematics teaching. First testimonies for solution methods we can find already on old Babylonian cuneiform plates ([8], p. 13, [30]):

a) "The surface and my confrontation I have accumulated: 0;45 is it.

b) 1 , the projection, you posit.

c) The moiety of 1 you break.

d) $0 ; 30$ and $0 ; 30$ you make hold.

e) $0 ; 15$ to $0 ; 45$ you append: by 1,1 is the equal side.

f) 0;30, which you have made hold, in the side of 1 your tear out: 0;30 the confrontation."

Comments:

The writing $0 ; 45(0 ; 15$ and $0 ; 30)$ is a representation of the fraction $\frac{3}{4}$ in the sexagesimalsystem: $0 ; 45=\frac{45}{60}=\frac{3}{4}\left(0 ; 15=\frac{1}{4} ; 0 ; 30=\frac{1}{2}\right)$ (Figure 2$)$.

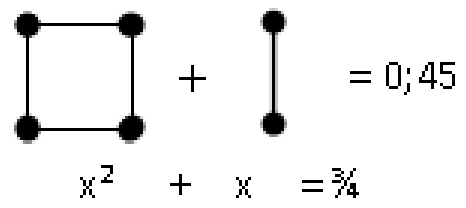

Figure 2

Referring to Høyrup [8] we give the following (geometric) interpretation:

a) "The surface and my confrontation I have accumulated: 0;45 is it.

The sum of the area of a square made of sticks and the length of such stick equals $\frac{3}{4}$. So this problem can be represented in modern terms by $x^{2}+x=\frac{3}{4}$ (Figure 3). This is a "formul-"ation still forbidden for Viete more than three thousand years later, because "inhomogeneous" magnitudes as areas and lengths were not allowed to be added together! Furthermore, the sticks of equal unknown length seem to be handled as if their length was already known. So, one can think here that "working backwards" was used implicitly. (Of course, every solution process of a modern equation can be seen in this way! Therefore "algebra" and "analysis" have been often used as synonyms at Descartes time.)

b) "1, the projection, you posit." 


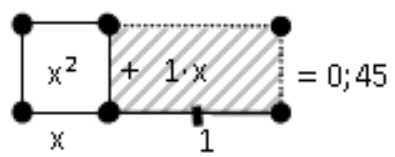

Figure 3

This is very tricky, because in this way one can interpret that the (unknown) length of the stick was transformed into an area (shaded) of the same measure by multiplying with the length 1 of the unit.

c) "The moiety of 1 you break, 0;30 and 0;30 you make hold."

The stick of length 1 is broken into two parts of length $\frac{1}{2}$. The ends are put together, form-ing a square of area $\frac{1}{2} \cdot \frac{1}{2}=\frac{1}{4}$ (Figure 4 ).

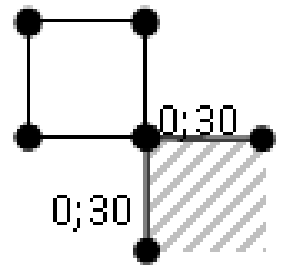

Figure 4

d) "0;15 to 0;45 you append: by 1, 1 is the equal side."

This shaded square with area $\frac{1}{4}$ adds up with the area of the grey "angle" $\frac{3}{4}$ to a total area of 1 . The corresponding quadrilateral is equilateral with side length 1. Obviously, we have here the literal process which we call today "quadratic completion", nearly four thousand years ago (Figure 5)!

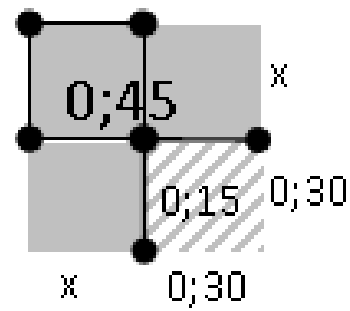

Figure 5 
e) "0;30, which you have made hold, in the side of 1 your tear out: 0;30 the confrontation."

As $x+\frac{1}{2}=1$ is also true, we have to subtract $\frac{1}{2}$ from 1 and get so $\frac{1}{2}$ for the length of the sticks, you have put together (Figure 6).

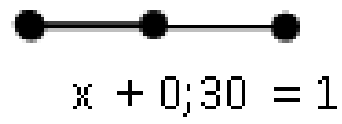

Figure 6

What kind of chances and stimuli this material might give to mathematics instruction? Here are some suggestions:

- Of course, one might give the "original text" ( Høyrup's [8] translation a) f)) to (teacher-)students with more or less comments and let them find possible interpretations, let them compare with the interpretation just given and let them discuss this.

- Normal pupils of grade 8 can be given the following (initial) problem (examples are taken from the textbook MatheNetz Vol. 8 (for grade 8), E3, p. 99.):

There is a square of unknown side length $x$. Place on one of its sides a rectangle of breadth $x$ and length 1 . The total area is $\frac{3}{4}$.

If necessary and depending on the amount of freedom you want to give to your pupils, you might (let them) add drawings similar to those in b). Furthermore, you might supplement even the main idea of the "Babylonian" method (separate the rectangle in two congruent parts and move them in such a way, that you can complete the figure into a square as shown above).

Then you might pose the following questions:

i) How large is $x$ ?

ii) Now the total area should be $3 \frac{3}{4}$ (and not $\frac{3}{4}$ ). What is $x$ now?

iii) Determine $x$, if the supplemented rectangle has a length of 2 and the total area is 3 .

iv) Invent similar problems.

v) Try to reverse the aforementioned process: Given a solution, look for fitting problems. Given a square with given area, which is dissected into two squares (one with given area) and two rectangles. Try to rearrange the "unknown" square and the two "partly" unknown rectangles in such a way that you receive only one rectangle of given area. Formulate an appropriate problem. 
Here you have not only the possibility for implicit training of working backwards, but also for changing representation. There are many possibilities to move back and forth between algebraic and geometric representation of quadratic equations. Of course, discussing zeros of graphs of quadratic functions might lead to another well-known representation.

\section{Example 2: The method of false position [31]}

The method of false position is of similar importance as changing representation. It had been already applied by ancient Egyptian mathematicians [2] and can be seen, e. g., in relation to the "regula falsi", the method of successive approximation (up to modern forms of iterations) and working backwards [27].

Some time ago my students had to make some practice in teaching. The subject was fractions in grade 5 .

In the first lesson in her life one of our student teachers presented the following problem to fifth-graders:

Peter gets a specific amount of pocket money for one week. He spends $\frac{3}{10}$ for a ticket for a movie. He buys a cake for $\frac{1}{4}$. He likes ice-cream very much, therefore he buys one for $\frac{1}{5}$. Finally he buys chewing-gum for $\frac{1}{10}$. At the end of the week there is $1.50 €$ left. How much pocket money Peter got in this week?

You have to take into account that the pupils had the following prerequisite knowledge about fractions:

- They learned some basics about fractions and different representations.

- They knew how to expand and how to cancel fractions.

- They made first experience with the addition of fractions with the same denominator.

Two girls presented the following solution at the blackboard ( $\mathrm{P}=$ pupil):

P: Let's assume that he receives $20 €$ in this week. Now we use and check the given data.

One pupil drew a long line at the blackboard and marked 0 at the beginning and 20 at the end of this line. Subsequently, she divided it into 20 parts of equal length (Figure 7).

Then they started - beginning at 0 - in marking the appropriate amount of money after changing all given fractions into fractions with denominator 20 (Figure 8). 


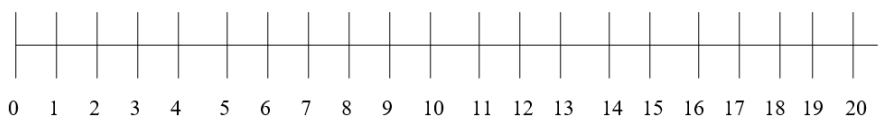

Figure 7

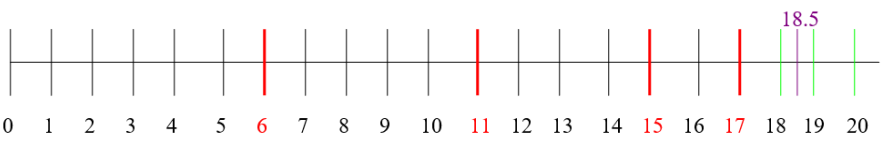

Figure 8

P: First Peter spent $6 €$ for the movie (first red line), than he bought a cake for $5 €$. Further-more the ice-cream was $4 €$. Finally he had to pay for the chewing-gum $2 €$. So we come to $17 €$. Then there should be a rest of $1.50 €$. So we come to a total of $18.50 €$. But there would be still $1.50 €$ left!?

The student teacher suggested now to make another trial, because - quite obviously - the assumed solution of $20 €$ must be wrong. So this thought process of the pupils was brought to an end by the teacher student.

Another possible continuation could have been as follows ( $\mathrm{T}=$ teacher):

T: So you have still some money left. Or: So you don't have left $1.50 €$ but $3 €-$ twice as much you should have. What to do now?

P: Possible reaction: If the amount left is twice as much we should have, perhaps we assumed also twice as much pocket-money than Peter should have at the beginning of the week. So we have to divide $20 €$ by 2 and get $10 €$.

It might follow now a check (verification) of this new assumption.

The process offered by the pupils can be interpreted as the beginning of the procedure of the well-known method of "false position". Of course, by drawing a number line, one can also say that the pupils made three changes representation: first, they changed the problem from a problem with fractions into a problem with integers; second, they made a visual representation of the numbers and, third, they represented the addition of numbers by the composition of lines of appropriate lengths.

\section{Discussion and outlook}

By presenting these two examples I try to point out the following issues: 
- Ex. 1 can help to make clear, that examples from history can foster problem solving abilities of pupils from today, especially using the power of visualization. It is especially important to give more meaning to abstract routines as solving quadratic equations and, therefore, to give the opportunity to the pupil to improve their understanding.

- Ex. 2 can help to clarify that knowledge of the teacher about problem solving processes and methods from history might help to become aware of, interpret, understand and appreciate problem solving processes of pupils from today in a deeper and more encompassing way. Thus, appropriate studies of and experience with history of mathematics might help (in addition to learning-teaching-experiments [10] (Kilpatrick's young pupils were most successful when applying "successive approximation" (similar to "false position") to solve word problems) and learning theories) to foster teachers' competence to identify powerful methods in the thoughts of pupils. In this way the teacher might become more sensitive for the capacity of pupils, too. This might help to improve teaching abilities, not only of pre-service teachers and beginning mathematics teachers.

Such classroom experience results in a major reinforcement of my motivation to carry out an analysis of mathematical thought processes and heuristic methods in history of mathematics in more detail ([25], [26]).

\section{References}

[1] J.S. Bruner, Entwurf einer Unterrichtstheorie, Pädagogischer Verlag Schwann, Düsseldorf, 1974.

[2] A. B. Chase, The Rhind Mathematical Papyrus, NCTM, Reston, 1986.

[3] E. Claparede, La psychologie de l'intelligence, Scientia Nov (1917), 335.

[4] J. Cukrowitz and B. Zimmermann, MatheNetz Ausgabe N; Klasse 8; Gymnasien, Westermann Schulbuchverlag, Braunschweig, 2000.

[5] J. Dewey, How we think, Prometheus Books, Buffalo, New York, 1991.

[6] E. v. Glaserfeld, Radical Constructivism in Mathematics Education, Mathematics Education Library, Vol. 7., Kluwer Academic Publishers, Dordrecht/Boston/London, 1991.

[7] L. Haapasalo and K. Sormunen, Towards Meaningful Mathematics and Science Education, Proceedings on the 19th Symposium of the Finnish Mathematics and Science Education Research Association 86, Joensuu, 2003.

[8] J. Høyrup, Lengths, Widths, Surfaces. A Portrait of Old Babylonian Algebra and Its Kin, Springer, New York, Berlin, Heidelberg, 2002. 
[9] C. Janvier, Problems of Representation in the Teaching and Learning of Mathematics, Lawrence Erlbaum Associates, Hillsdale, 1987.

[10] J. Kilpatrick, Analyzing the Solution of Word Problems: An Exploratory Study, Dissertation Stanford, 1967.

[11] J. Kockelmans, Toward an interpretative or hermeneutic social science, Graduate Faculty Philosophy Journal 5, no. 1 (1975), 73 - 96.

[12] P. Kupari, Mitä kansainväliset arviointitutkimukset kertovat maamme matematiikan opetuksen ja oppimisen tilasta? (What do International Comparative Studies tell us about the Situation of Mathematics Learning and Teaching in our Country?) Lecture hold on the Annual Symposium of the Finnish Mathematics and Science Education Research Association, Joensuu 28.9.2002., (Cf. Kupari 2002a), 2002.

[13] P. Kupari, Finnish students' mathematical literacy in PISA 2000 study, in: Towards Meaningful Mathematics and Science Education, (L. Haapasalo \& K. Sormunen, eds.), Proceedings on the 19th Symposium of the Finnish Mathematics and Science Education Research Association 86, University of Joensuu, 2002a, 83 - 90.

[14] NCTM, Curriculum Standards for School Mathematics, Reston, 2000.

[15] T. Nunes, A.D. Schliemann, D.W. Carraher, Street mathematics and school mathematics, Cambridge University Press, Cambridge, 1993.

[16] G. Pólya, Mathematics and Plausible Reasoning, Vol. 2, University Press, Princeton, 1954.

[17] G. Pólya, How to Solve It, (2nd, ed.), Doubleday, New York, 1973.

[18] G. Pólya, Mathematical Discovery, Combined paperback edition, Wiley, New York, 1980.

[19] P. Reason and J. Rowan, Human Inquiry. A Sourcebook of New Paradigm Research, J. Wiley \& Sons, Chichester-New York-Brisbane-Toronto, 1987.

[20] A.H. Schoenfeld, Mathematical Problem Solving, Academic Press., Orlando, 1985.

[21] G. Seidel, Ordnung und Multimodalität im Denken mathematisch Hochbegabter: sequentielle und topologische Eigenschaften kognitiver Mikrozustände, Dissertation, Friedrich-Schiller-Universität Jena, 2001.

[22] M. Spitzer, Lernen. Gehirnforschung und die Schule des Lebens, Spektrum Akademischer Verlag, Heidelberg, Berlin, 2002.

[23] B. Zimmermann, Analyse des Problemlöseverhaltens bei Aufgaben aus der Inzidenzgeometrie. Eine exploratorische Untersuchung mit Schülern und Studenten, (Analysis of Problem Solving Behavior when solving Problems from Incidence Geometry. An exploratory Study with Pupils und Students.), Dissertation, University of Paderborn, Department of Mathematics, 1977.

[24] B. Zimmermann, Analyzing Problem Solving Processes involved with Problems from Incidence Geometry - An Exploratory Study, ERIC, no. ED 191 685, Columbus, Ohio, (1980).

http://www.eric.ed.gov/ERICWebPortal/search/detailmini.jsp?_nfpb=

true\&_\&ERICExtSearch_SearchValue_0=ED191685\&ERICExtSearch_SearchType_0=no\&accno=ED191685 . 
[25] B. Zimmermann, Heuristische Strategien in der Geschichte der Mathematik, in: Finden, Erfinden, Lernen - Zum Umgang mit Mathematik unter heuristischem Aspekt, (M. Glatfeld, ed.), Peter Lang, Frankfurt/M., Bern, New York, Paris, 1990, $130-164$.

[26] B. Zimmermann, Heuristik als ein Element mathematischer Denkund Lernprozesse. Fallstudien zur Stellung mathematischer Heuristik im Bild von Mathematik bei Lehrern und Schülern sowie in der Geschichte der Mathematik., Habilitation, University of Hamburg, 1991 http://users.minet.uni-jena.de/ bezi/Literatur/ZimmermannHabil-beliefshistoryofheuristicsinclABSTRACT. pdf.

[27] B. Zimmermann, Rekonstruktionsversuche mathematischer Denk-und Lernprozesse anhand früher Zeugnisse aus der Geschichte der Mathematik (Attempts to reconstruct mathematical Thinking- and Learning-Processes in early Testimonies from History of Mathematics), in: Kaleidoskop elementarmathematischen Entdeckens, (B. Zimmermann, ed.), Franzbecker, Hildesheim, 1995, 229 - 255.

[28] B. Zimmermann, On the Genesis of Mathematics and Mathematical Thinking- a Network of Motives and Activities Drawn from the History of Mathematics, in: Towards Meaningful Mathematics and Science Education, (L. Haapasalo \& K. Sormunen, eds.), Proceedings on the 19th Symposium of the Finnish Mathematics and Science Education Research Association 86, University of Joensuu, 2002, 29-47.

[29] B. Zimmermann, Darstellungswechsel als eine wichtige Methode zur Lösung von Problemen-schon in der Geschichte der Mathematik (Changing Representation as an important problem-solving method-already in History of mathematics), Der Mathematikunterricht 6 (2003), 5-16.

[30] B. Zimmermann, On the Legacy of G. Pólya: Some New (old) Aspects of Mathematical Problem Solving and Relations to Teaching, Teaching Mathematics and Computer Science 2 (2003a), 169-189.

[31] B. Zimmermann, Improving of Mathematical Problem-Solving-some new IDEAS from Old Resources, in: Posing and solving mathematical problems: Advances and new perspectives, (P. Felmer, E. Pehkonen, \& J. Kilpatrick, eds.), Springer, New York, Berlin, Heidelberg, 2016, 83-108.

BERND ZIMMERMANN

FRIEDRICH SCHILLER UNIVERSITY OF JENA

E-mail: bernd.zimmermann@uni-jena.de 